\title{
Cognitive Age and Consumption Pattern among Aging Population - Moderating Impact of Self Confidence and Social Involvement
}

\author{
Bazla Mukhtar ${ }^{1}$, Kazim Usman ${ }^{2}$, Muhammad Zubair ${ }^{3}$, Aqsa Baig ${ }^{4}$ \\ ${ }^{1}$ Lecturer, Institute of Business Management (IoBM), \\ ${ }^{2}$ Lecturer, Institute of Business Management (IoBM), \\ ${ }^{3}$ Assistant Professor, Institute of Business Management (IoBM), \\ ${ }^{4}$ Assistant Manager Implementation and Monitoring-Retail Banking, Meezan Bank Ltd.
}

\begin{abstract}
Pakistan has become one of the exciting markets for marketers due to the paradigm shift of the market, reduced regulation, and privatization of several enterprises. Despite several research studies on consumer behaviors, few researchers have studied the change in elderly consumers' choices and their behavior in the rapidly changing market. Therefore, this research investigates the influence of cognitive age on loyalty proneness, status consumption, and materialism level for Pakistani elders. It evaluates if social involvement and self-confidence can moderate these relationships. Elderly consumers residing in Karachi were the target population for carrying out data collection. The complete data collection process took 25 days, with completion of 710 questionnaires, out of which 676 were deemed reliable for this research study. The study results indicated that the Pakistani elderly with a younger cognitive age appear to be more materialistic and more driven to status consumption or vice versa. The results of the study did not indicate any significant relationship between loyalty proneness and cognitive age. The moderating influence of self-confidence for H1a (Materialism) and H3a (Loyalty to brand or product) in elderly consumers is significant. On the contrary, H2a (Status Consumption) was rejected, as self-confidence does not act as a moderator. For the hypotheses H1b Materialism), $\mathrm{H} 2 \mathrm{~b}$ (Status Consumption), and H3b (Social Involvement with Loyalty to brand or product), the moderating influence produced by social involvement in the case of senior consumers are found to be significant. This research has provided a more significant contribution to everneeded research in the Pakistani market, considering its market size and significance. This research will be a better contribution to the present literature. It can be useful to marketers as it provides valuable insights related to the seniors' consumption experience in the Pakistani market. Keywords: Cognitive Age, Materialism, Loyalty Proneness, Elderly, Consumers, Senior Market
\end{abstract}

\section{Introduction}

Pakistan has become one of the exciting markets for marketers due to the paradigm shift of the market, reduced regulation, and privatization of several enterprises (Ashiq and Asad, 2017). All these market changes are responsible for radical economic changes, which have improved the economy and affected consumers' choices. Rapid industrialization, higher educational priorities, and improvements in income are factors that have promoted luxury consumption. Despite several research studies on consumer behaviors, few researchers have studied the change in consumers' choices and their behavior in the rapidly changing market (Barak and Schiffman, 1981; Eastman and Iyer, 2005). Another reason for marketers' interest in the Pakistani market is the emerging economy having an excellent power distance culture. The Pakistani market is considered multi-hued and complicated because of the influence of local and western culture. All Pakistanis do not have a similar consumption pattern regarding the consumption pattern (Ashiq, U., and Asad, 2017; Tarka, 2019).

Different segments of the Pakistani market are studied; however, the senior market has not been adequately searched and addressed (Ashiq and Asad, 2017). It can be said that that this segment will grow to a greater extent in the next few years; therefore, it is imperative to consider this segment of the market. Considering the significance of age as an essential variable for market segments, researchers have presented to study and evaluate the importance of age to consumers' present behavior and attitude. Previously conducted studies have considered consumption patterns and consumer choices of Americans, Japanese seniors, Turkish seniors, Italian seniors, and some cross-cultural groups. Yet, the Pakistani market is still unexplored in this context. Thus, the present study has been carried out to overcome this research gap. This research is related to the influence of cognitive age on the consumption pattern to develop a proper understanding of Pakistani seniors (Iyer et al., 2017).

This research will contribute to the present literature and provide better information about seniors' consumption experience in developing countries with emerging economies. It is imperative to evaluate the impact of cognitive age and cross-culture measurement of cognitive age considering the Pakistani market development (Sulaiman, Ali, and Khatoon, 2019). This research investigates the influence of cognitive age on loyalty proneness, status consumption, and materialism level for Pakistani elders and evaluates if social involvement and self-confidence can moderate these relationships or more (Islam et al., 2017; Zia, Ifthikar, and Raza, 2017).

This research will provide a clear picture of the Pakistan market and help marketers serve this market segmentation. Furthermore, this research is also an exceptional contribution to the study. It demonstrates whether it is beneficial to consider the Pakistan market's cognitive age construct and Age with consumer behavior variables. The term elderly or senior is used in this research for the presentation of the same population. The elders considered for this research are sixty-five years or more. The literature review of studies carried out on the senior market, self-confidence, materialism, cognitive age, social involvement, loyalty, and status consumption 
demonstrates this research. The next section is related to the presentation of the research methodology, sampling approach, and sample. Lastly, findings and discussion related to results in this research report are also presented.

\section{Literature Review \\ The Pakistani Senior Market}

Due to increased life expectancy, an emerging issue in Pakistan is demographic aging. It is a developing economy, and demographic transition is the prime factor (Ashiq and Asad, 2017). The increase in older people compared to the total population has revealed three times increase during 3.5 decades. According to the reports, the population will increase to 23.76 million, showing a rise of $9.3 \%$ in the elderly population in 2030 . This population group in Pakistan has significant characteristics and comprises people in different rural regions. Also, there is approximately $30 \%$ in several age groups for more than 80 years, and the majority of these people are females (Islam et al., 2017; Sulaiman, Ali, and Khatoon, 2019). According to another study, the senior market segment is expected to grow by 20 percent by 2050 , which will also be representing 300 million consumers. It is also an attractive and exciting market segment targeted by researchers as no one has researched and analyzed this segment properly and the impact of this segment on materialism (Verma and Gupta, 2014).

In Pakistan, seniors are culturally conditioned to believe that they will be looked after becoming old by their children. However, there is a decline in the traditional family system, and the interest of younger people in urbanization has also increased the chances that elders may have to live alone. Due to the change in family structure, the seniors face significant emotional and financial concerns. Several studies have demonstrated the influence of growth in the elder segment, significance of family and technological behavior (Ashiq and Asad, 2017); however, limited studies have presented the impact of cognitive age on people's behavior.

\section{Cognitive Age}

By definition, cognitive age is the perceived age assumed by the individual, and it is different from the individual's actual age. For example, those in pre-teens want to be older than those who want to be younger. Numbers of researches have been conducted to know the exact meaning of cognitive age. One research is defined as it comprises different aspects of age than the chronological Age (Barak and Schiffman, 1981). According to the research, it is also defined as one of the perceived age and considered one of the self-concept elements (Wylie, 1974).

Age is an essential factor of segmentation. While segmenting a product, this factor is analyzed and researched thoroughly. Age can predict consumer behavior very well. Most of the cognitive age consumers are better predictable than others because they are more likely to be loyal. According to a research study conducted by Karasawa et al. (2011), the majority of the old age people in Japan perceive themselves young concerning their cognitive age and tend to engage themselves in more social activities and are more sensitive to market trends and tend to switch brands without hesitation.

On the contrary, a minority who perceive their cognitive age more than their chronological age tend to be more loyal to their existing brands. According to Deary et al. (2004), cognitive age plays a vital role in determining a person's cognitive capacity of evaluation and analytical skills. People with greater cognitive age are likely to possess poor evaluation and low analytical skills. Thus, they feel reluctant to switch brands as switching brands requires extensive assessment and analysis. Hence their loyalty proneness towards brand loyalty is high (Deary et al., 2004). From the above discussion, it can be concluded that cognitive age does play a prominent role in understanding the consumption behavior of the elderly. Because of the growing age, change in needs, experiences, environment, and surroundings can or cannot lead to a change in the self-image of the elderly (Mathur and Moschis, 2005). Therefore, this can be considered an important variable that can impact market segmentation and marketing strategies of different brands.

\section{Social Involvement and Self-Confidence}

According to social aging theories, seniors engaged in different compensatory activities can remain psychologically and socially fit. Usually, the aging period is considered one of the stages of a person's life, characterized by the wealth of experience accumulated in the past and has several new properties and signs not found in the early development periods (Cristofalo, 1998). However, there is little knowledge about aging's psychological mechanisms and how to neutralize this process's negative manifestations. Old age, like any other, has its positive and negative sides. It is associated with losses and has advantages, allowing a person to live more actively this period of his life, achieving interests, inclinations within those optimal in terms of opportunities and needs of an older person (Mathur and Moschis, 2005). Research shows that younger cognitive age is made up of self-confidence. When people are more satisfied, they are more likely involved in social interactions. There is more usage of the internet among the people with younger cognitive age, and along with that, it showed that they are motivated towards high tech products, these were the finding of Chua et al. (1990). Research also found out that people with higher cognitive age have lower participation in culture-related activities. They do not have an interest in any fashions. They are more likely to be loyal to the brand because they think they have the best brands. However, people with a younger cognitive age are more likely to adopt the change and are considered innovators because they tend to seek new experiences and try to buy new things and switch quickly to another brand (Mathur and Moschis, 2005). Cognitively younger seniors exhibit greater self-confidence (Wilkes, 1992). Social aging's 'activity hypothesis' indicates that seniors participate in 
compensatory behaviors to stay socially and cognitively healthy (Smith \& Moschis, 1985).

Islam et al. (2017) revealed that seniors of younger cognitive age have more social involvement and greater self-confidence, and their lives are usually more active and healthier. However, the study by Ashiq and Azad (2017) has not presented the impact of cognitive age on social involvement and self-confidence level. But the research has demonstrated that self-confidence and social participation have significant importance for elders in Pakistan as Pakistan has a collectivist culture with more power differences, and family is thought of as the vital part. Literature studies have not considered how the influence is produced by social involvement and selfconfidence on cognitive age effects and other variables for consumer behaviors such as loyalty, status consumption, and materialism in Pakistani culture (Sharma, 2011). Therefore, considering the significance of family in Pakistani cultures and how it affects different people, it is imperative to examine the association between other variables.

\section{Materialism}

Materialism is seen as a personality trait and value. The personality trait concept is tangibility, envy, possessiveness, and absence of generosity (Zia, Ifthikar, and Raza, 2017). From the value aspect, it is with success, happiness, and centrality. Materialist consumers pay more importance to external belonging values, and compared to others, are respected more. McCormick et al. (2019) demonstrated that materialist measurement's key dimensions include uniqueness, social recognition, and happiness. They also presented the importance of material possessions for the promotion of self-regard. Some other researchers also revealed that self-identity and well-being could improve by materialism (Jain, 2018).

Different researchers recommended that materialistic values be found in different sub-cultures and cultures; however, differences in materialism can occur from several cultural and economic influences, and the materialism concept can represent different things in different cultures. Swimberghe et al. (2018) revealed that older consumers present more interest in the functions instead of social advantages associated with the products; however, the perception of younger and older people regarding materialism is different. Thus, seniors feeling like youngsters have materialist feelings like younger consumers.

Exploring materialism from marketers' point of view is very important as it creates a lack of satisfaction with the existing product and services (Flynn et al., 2016). Thus, materialistic consumers are expected to use products and services that will satisfy their unfulfilled desires. Such consumers update themselves with new products and services, which means more demand for products and services from marketers' point of view. Consumer materialism affects the different aspects of consumer behavior. For example, it has been related to overconsumption (Lang and Armstrong, 2018), unethical consumption (Chowdhury and Fernando, 2013), attitude towards advertisements (Osmonbekov et al., 2009), attitudes (Lang and Armstrong, 2018), and brand engagements (Sprott et al., 2009). Other than this, materialism is the motivation for successful marketing of products and services (Flynn et al., 2016), used as a segmenting variable (Cleveland et al., 2009), and is said to correlate with social needs consumption behavior.

In the other research done by Dogan (2015, p. 566), he explains that since older consumers are much engrossed in obtaining functional rather than the social benefits of the products. "the older people materialism perception is different from, the younger people materialism perception" and the older ones who perceive themselves as being young consume more than those who are young. So seniors are found to be more materialistic. As shown in many types of research, senior consumers tend to be more materialistic because they want to show that they are still young and can also possess and consume whatever the younger or pre-teens can consume (Dogan, 2015).

Different research studies have also presented that materialism may associate with social positioning and drive for pursuing a desirable image (Pino, Guido, and Nataraajan, 2017). Pakistan has a collectivist culture. This culture can maintain a person's social identity or a group, especially for senior people who perceive themselves as youngsters. Therefore, they are considered active consumers. This research suggested that seniors with cognitive younger feelings are more materialists than other elders (Islam et al., 2017).

Furthermore, other studies demonstrated that people driven for some social purpose are more materialists than those who consider possessions as an identity source (Swimberghe et al., 2018; Pino, Guido, and Nataraajan, 2017). Due to the family significance in Pakistani culture, it is thought that these relationships also exist for seniors. Following hypotheses can be proposed in this context;

H1: Pakistanis elders having an older cognitive age possess lower materialism level as compared to elders with a younger cognitive age

H1a: The association between materialism and cognitive age is stronger for Pakistani elderly having high selfconfidence level as compared to Pakistani elders with low self-confidence level

H1b: The association between materialism and cognitive age is stronger for Pakistani elderly having high social involvement level as compared to Pakistani elders with low social involvement level

\section{Status Consumption}

The term status consumption is the motivational process used by individuals to improve social standing with conspicuous consumption of different products, symbolizing status for the person and his significant others (Swimberghe et al., 2018). The level is associated with wealth evidence with power and conspicuous consumption associated with respect, envy, and 
consideration rather than product value. Status consumers present their information to reference groups by making surrounding with visible evidence for claimed higher rank. Correia, Kozak, and Kim (2019) explained that status consumption might occur from the snob effect or bandwagon. Bhaduri and Stanforth (2016) demonstrated conspicuous consumption related to different cultural aspects considering culture and luxury consumption concepts. Some aspects of luxury marketing are studied; however, evidence connected to elderly marketing is limited.

Amatulli et al. (2018) revealed that luxury consumption could vary from one individual to another. Such a situation provides that younger Pakistanis are motivated to spend for internal or internal reasons similarly as presented status and style motivation. Pino, Guido, and Nataraajan (2017) also revealed that consumers are motivated to be the independent, indulgent, reward, and pamper. They presented that luxury spending is affected by both cultural and psychological elements. Bhaduri and Stanforth (2016) revealed that luxury consumption is associated with self-esteem needs, selfconcept, social motivations, and personal aspiration. Ki, Lee, and Kim (2017) demonstrated that people who feel cognitively young than chronological age have more spending on luxury products. Therefore, cognitively younger seniors feel motivated for consumption for status and developing social identity; this has suggested that cognitive elder seniors are low motivated compared to cognitively young seniors. Swimberghe et al. (2018) also suggested that cognitively younger elders are focused on luxury consumption, and those having increased social involvements are involved in this consumption because of status and luxury. The following hypotheses are presented in this context.

$\mathrm{H} 2$ : Pakistanis elders having an older cognitive age possess lower status level consumption as compared to elders with a younger cognitive age

H2a: The association between status consumption and cognitive age is stronger for Pakistani elderly having high self-confidence level as compared to Pakistani elders with low self-confidence level

$\mathrm{H} 2 \mathrm{~b}$ : The association between status consumption and cognitive age is stronger for Pakistani elderly having high social involvement level as compared to Pakistani elders with low social involvement level

\section{Loyalty to Product or Brand}

Brand loyalty can be defined as a measure of scale that determines how consumers bear loyalty to a particular brand and how their commitment is affected by the change in price, specifications, quantity, and quality of the product. If the consumers' behavior changes significantly concerning the above variables, loyalty is low towards brand loyalty. Brand loyalty is the preference of the consumer to buy a specific brand in a product category. When the consumer thinks that the particular company is providing a product that serves its purpose at the right price, they develop an emotional attachment to that brand.
He or she keeps on buying it again and again. People with high cognitive age tend to possess high brand loyalty (Aaker, 1991).

As per Rosenbaum, Percy, and Pervan (2011), brand loyalty strengthens the bond between the company and the consumers. To such an extent, consumers with high brand loyalty are willing to pay more to attain a unique value from the company in the form of high quality and high satisfaction and happily sacrifice/forgo the benefits they could have enjoyed from other brands. People with greater cognitive age are willing to pay more to attain a unique value, which increases their level of satisfaction. In contrast, people of less cognitive age are less loyal to brands as they tend to be more optimistic and switch to other brands if they are getting more benefits by paying less (Rosenbaum, Percy, and Pervan 2011).

According to (Srivastava 2007), companies successfully build long-term relationships with their consumers through tailor-based services, offering discounts, and satisfactory after-sales services. The loyalty proneness of consumers towards brand loyalty increases. People with greater cognitive age develop a high sense of trust in the brand and feel reluctant to switch to other brands as they fear that they might not be offered the same benefits by the new brand they choose. Touzani and Temessek (2009) define brand loyalty as a consumer's repetitive and systematic purchasing pattern of a particular brand. People with greater cognitive age tend to have a repetitive buying pattern as they feel reluctant to switch to other brands. Hence with time, they become loyal to the brand (Touzani \& Temessek, 2009).

A traditional assumption shows that people of higher age groups can be seen to be more brand loyal. It is tough to persuade them to try a new product than the younger age group motivated by innovation when brand loyalty is considered (Lambert Pandraud, Laurent and Lapersonne, 2005). Lambert Pandraud, Laurent, and Lapersonne (2005) established that while analyzing the automobile purchases that the older consumers purchased the same automobile brand more frequently and considered fewer brands and chose well-established brands rather than going through all the brands available. According to Lipke (2001), brand loyalty is deteriorating amid all age groups, and the maximum noteworthy decline can be found in the old-aged shoppers. It indicates that the adult consumer market is slow in terms of adaptiveness to change; people who do not desire or are not interested in novel brands or products are briskly increasing (Lipke, 2001).

In another research study by (Parpis 2002), people who engage themselves in experimentation are cognitively brave and open to new experiences with low brand loyalty. They are not hesitant to switch to new brands to enjoy a unique and probably better experience. People of greater cognitive Age tend not to indulge in experimentation due to fear of adverse consequences that may occur; hence, their brand loyalty is high (Parpis, 2002). Lambert Pandraud, Laurent, and Lapersonne 
(2005) study that people with more significant cognitive age tend to be more loyal to their existing automobile brand in the automobile industry. They want to avoid the hassle of complex purchase procedures and prefer old established brands over new ones. However, people with low cognitive age are less loyal to their automobile brands. They are ready to indulge in the hassle of complex purchase processes to buy the best product (Lambert Pandraud, Laurent, and Lapersonne, 2005).

Data and research from the different researchers and authors tell that consumer buying behavior is somewhat mixed when considering chronological age. The older and younger consumers must show the same intensity of brand loyalty, but unfortunately, that is not the case. The cognitive age represents the brand's loyalty; the younger the person would be cognitive, the less loyal he will be (Szmigin and Carrigan, 2001). Different research studies have demonstrated that elders have more brand loyalty than younger ones, which simplifies their decision to buy (Lerma, Morais, and Luna, 2017). The reason for this relationship is earlier associated with these brands. In Pakistan, few elders reached this age with some brand choices, enhancing their loyalty to the brand. Considering cognitive age, researchers revealed that cognitively young consumers have brand switching behavior, trying new brands and are more confident in their choices.
Bhaduri and Stanforth (2016) mentioned that senior consumers have relatively more loyalty to different brands regarding luxury brands. During the liberalization period, Pakistani elders have more options for brands and products, and therefore, their commitment to brands has changed. Thus, findings suggested that senior cognitive elders have more loyalty (Ki, Lee, and Kim, 2017). Further, it also suggests that Pakistani seniors are more socially involved and are self-confident, brand, or product loyal. They usually prefer to stick to a single brand instead of making several choices.

The following evaluate the association of cognitive age with brand loyalty:

H3: Pakistanis elders having an older cognitive age possess lower product/brand loyalty as compared to elders with a younger cognitive age

H3a: The association between product/brand loyalty and cognitive age is stronger for Pakistani elderly having high self-confidence level as compared to Pakistani elders with low self-confidence level

$\mathrm{H} 3 \mathrm{~b}$ : The association between product/brand loyalty and cognitive age is stronger for Pakistani elderly having high social involvement level as compared to Pakistani elders with low social involvement level

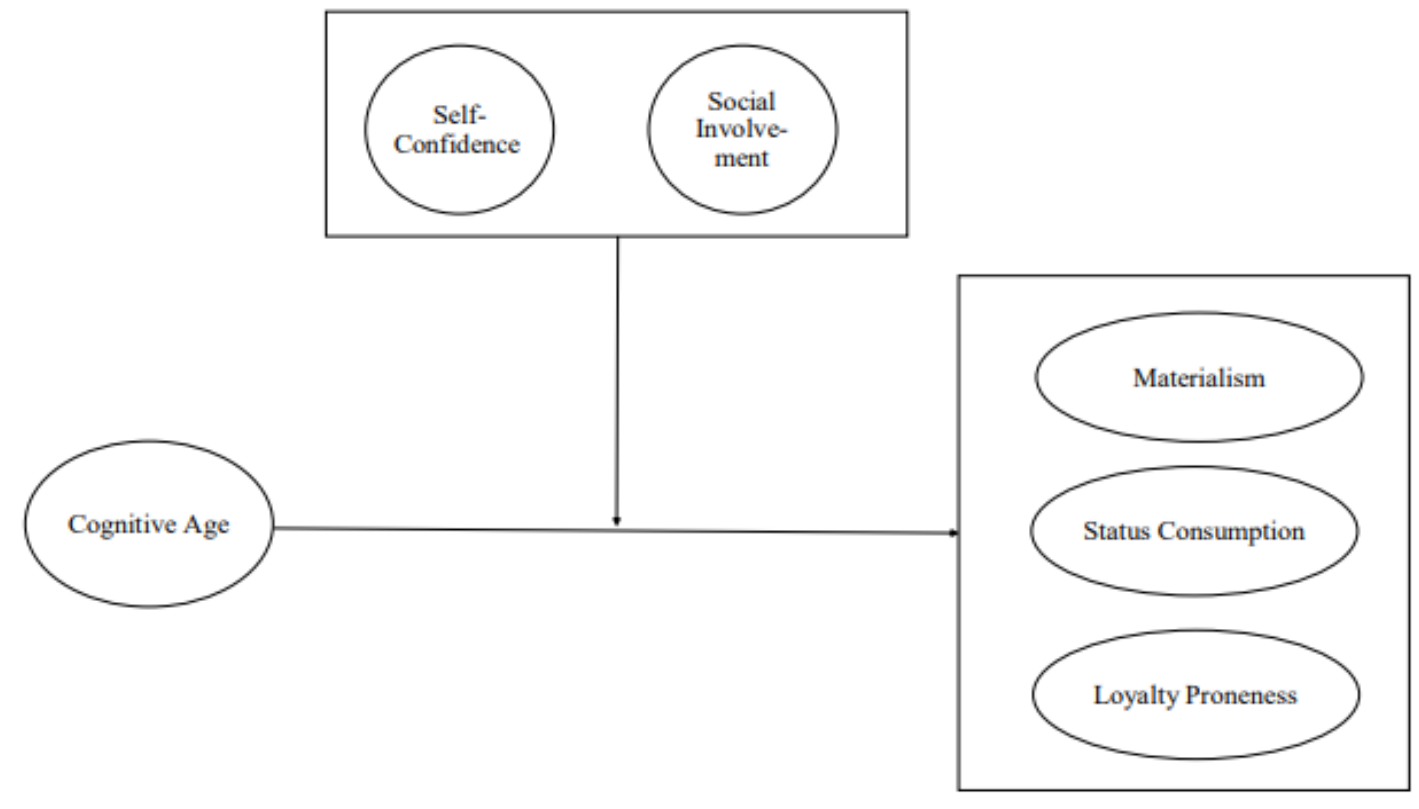

Figure 1: Conceptual Model (Iyer, Eastman, Sharma \& Eastman, 2017)

\section{Methodology}

Sample

For this research, the data collection was carried- out from elderly consumers of the biggest city of Pakistan, i.e., Karachi. Considering data collection procedures presented by Jones and Reynolds (2006), graduate students were recruited and then trained for administering the survey. Proper training was provided to the students regarding data collection processes, and instruction was given to them to contact senior consumers, present the research study nature and then ask them to participate in research by completing the questionnaire. Students showed their eagerness to participate in the study and were promised complete confidentiality. The questionnaire was given immediately, and the student helper helped them clarify their understanding of questionnaire items (Iyer, Reisenwitz, and Eastman, 2008). 
These consumers participating in the research provided their contact information and name to verify that they have participated in the study. At the end of this day, helpers gave the filled questionnaire to the researchers. The complete data collection process took 25 days, and they completed 710 questionnaires in this time duration. After the collection of questionnaires, follow-up calls were made to participants. After this, the researcher reviewed the researcher to identify and eradicate the questionnaires of consumers who did not meet the inclusion criteria concerning age. After this process, 676 responses were reliable. $69 \%$ of these respondents were males (table 2) with a high degree or under graduation (Table 3), 47\% were employed yet (table 4).

Table 1 Age

Table 2 Gender

\begin{tabular}{llll}
\hline & & Frequency & Percent \\
\hline Valid & Male & 210 & 31 \\
& Female & 466 & 69 \\
& gen & 1 & .3 \\
& Total & 676 & 100.0 \\
\hline
\end{tabular}

\begin{tabular}{llll}
\hline & & Frequency & Percent \\
\hline Valid & $30-40$ & 94 & $14 \%$ \\
& $41-50$ & 163 & $24 \%$ \\
& $51-60$ & 129 & $19 \%$ \\
& $61-70$ & 117 & $17 \%$ \\
& $71-80$ & 136 & $20 \%$ \\
& $81-90$ & 37 & $5 \%$ \\
& Age & 1 & .3 \\
& Total & 676 & 100.0 \\
\hline
\end{tabular}

Table 2 Education

\begin{tabular}{|c|c|c|c|}
\hline & & Frequency & Percent \\
\hline \multirow[t]{5}{*}{ Valid } & Intermediate & 269 & 39.8 \\
\hline & Bachelors & 280 & 41.4 \\
\hline & $\begin{array}{l}\text { Masters and } \\
\text { above }\end{array}$ & 127 & 18.8 \\
\hline & edu & 1 & .3 \\
\hline & Total & 676 & 100.0 \\
\hline
\end{tabular}

Table 3 Employment Status

\begin{tabular}{llll}
\hline & & Frequency & Percent \\
\hline Valid & Yes & 318 & 47.0 \\
& No & 358 & 53.0 \\
& emp & 1 & .3 \\
& Total & 676 & 100.0 \\
\hline
\end{tabular}

\section{Construct Operationalization}

From the previously conducted research studies, different items of these questionnaires were adopted. The cognitive age factors developed from Barak and Schiffman's (1981) study ad considered the indicators of look, feel, act, and interests. This scale measured intervals of 10 years ranging from 30 years to 90 years (table 1 ). For the measure of all other items, a Likert scale based on seven points was used where one represented strongly disagree, while seven presented strongly agree and four were neutral (Jones and Reynolds, 2006).

\section{Measures and Purification}

After evaluating different indicators for quality measurement, each factor was submitted for the confirmation factor analysis. Various factors loadings were significant at 0.01 level, with the reliabilities of all individuals above 0.4 value, and composite reliability has a value of almost 0.7 . After examining different individual factors, reduced items were then subjected to analysis of confirmatory factors using maximum estimation with the aid of LISREL 8.5. With the support of information provided regarding validity and reliability (Barak and Schiffman (1981) as Chi-square value is significant for the 
measurement model ( $p<0.001,440.70$ with 71d.f), other measures of goodness of fit of the model to information.

Table 4 Items for Measurement

\begin{tabular}{|c|c|c|c|}
\hline Items & & $\begin{array}{l}\text { t-values } \\
\text { (Standardized } \\
\text { loading) }\end{array}$ & Source of Adoption \\
\hline \multirow[t]{4}{*}{ Cognitive Age } & $\begin{array}{l}\text { Several times, I have the feeling that I } \\
\text { am in my ........ }\end{array}$ & $26.83(0.85)$ & Barak and Schiffman (1981) \\
\hline & Several times, I look like I am in my & $27.09(0.86)$ & \\
\hline & $\begin{array}{l}\text { My usual interest is similar to the person } \\
\text { in her/his........ }\end{array}$ & $27.27(0.86)$ & \\
\hline & $\begin{array}{l}\text { I usually love to do different things, } \\
\text { which are usually done by a person in } \\
\text { her/his ....... }\end{array}$ & $22.65(0.76)$ & \\
\hline \multirow[t]{3}{*}{ Status Consumption } & $\begin{array}{l}\text { I would prefer to buy any product } \\
\text { because it enhances my status }\end{array}$ & $26.44(0.85)$ & Eastman et al. (1999) \\
\hline & $\begin{array}{l}\text { I have a keen interest in new products } \\
\text { presenting status }\end{array}$ & $27.30(0.88)$ & \\
\hline & $\begin{array}{l}\text { I could pay more for any product if it is } \\
\text { having the status }\end{array}$ & $22.66(0.77)$ & \\
\hline \multirow[t]{3}{*}{ Materialism } & $\begin{array}{l}\text { I love to own expensive things, which } \\
\text { can make others think me different and } \\
\text { unique }\end{array}$ & $27.06(0.85)$ & Sirgy et al. (2012) \\
\hline & $\begin{array}{l}\text { I mainly prefer to purchase expensive } \\
\text { brands and products to make me feel } \\
\text { different and unique }\end{array}$ & $32.59(0.95)$ & \\
\hline & $\begin{array}{l}\text { I prefer to buy expensive things to look } \\
\text { distinctive }\end{array}$ & $29.45(0.89)$ & \\
\hline \multirow[t]{4}{*}{$\begin{array}{l}\text { Brand or } \\
\text { Loyalty }\end{array}$} & $\begin{array}{l}\text { I usually buy the same brand, which I } \\
\text { prefer always }\end{array}$ & $21.30(0.73)$ & Raju (1980) \\
\hline & $\begin{array}{l}\text { I hate to switch the brand or product } \\
\text { when I am used to it }\end{array}$ & $25.71(0.83)$ & \\
\hline & $\begin{array}{l}\text { I barely make the decision to use } \\
\text { anything else, if I like a brand }\end{array}$ & $28.23(0.89)$ & \\
\hline & $\begin{array}{l}\text { Instead of the fact that certain services } \\
\text { and products are present in different, I } \\
\text { usually prefer to buy the same brand }\end{array}$ & $24.19(0.80)$ & \\
\hline
\end{tabular}

\section{Construct Validity Assessment}

There was an examination of model validity after this process. Each of these items presented acceptable loadings as the path estimates were more significant than 0.50 , and the $t$-value was $>2.0$, which indicated convergent validity, which was sufficient (Eastman et al., 1999). Regarding discriminant validity, no confidence intervals of the phi matrix have 1.00. The variance amount for each of these constructs was then compared with phi estimates squares, and estimation for all of these constructs was found greater than estimates of squared phi, which demonstrated sufficient discrimination among different variables. All these factor loadings were different from zero significantly, which has been shown by the large t-values consistently (Sirgy et al., 2012). The composite scores of reliability were calculated to determine scale reliability, and ranges were above 0.6 (0.73-0.93). Therefore, it can be demonstrated that measures possess sufficient reliability and validity for hypothesis model testing.

\section{Structural Model Estimation}

Testing the hypothesis, as presented in table 7 using structural equation modeling performed by LISREL (Raju, 1980). The market variable approach was utilized for evaluating common method variance, and there was no evidence regarding its role in the bias of outcomes.

\section{Analysis of Data}

Subgroup analysis was carried out to test moderating effects. Three groups of respondents were made, considering these effects, and $35 \%$ were considered low on the dimension, while $35 \%$ were deemed high. On the contrary, the elimination of the middle $30 \%$ was to be carried out to maximize contrast between high and low groups for enhancing the effectiveness of other statistical tests (Eastman et al., 1999). As demonstrated in table 8, this process is utilized to examine the moderators, 
including self-confidence and social involvement, and three dependent measures, i.e., brand or product loyalty, status consumption, and materialism. For all of these, regression analysis was carried out with loyalty, status consumption, or materialism as a dependent variable while considering cognitive age as independent for all respondents in low and high moderator groups. After that, the second regression was to be performed by allowing different coefficients for these two groups.
Furthermore, a Chow test was the performance on sum differences of squared residuals from two regressions to determine statistical difference significance in the cognitive age coefficient between low and high groups. The same process was carried out for all moderators, and this is considered an accepted standard process for testing moderation.

Table 5 Construct correlations, Standard deviation (SD), Mean, Extracted Variance

\begin{tabular}{lllll}
\hline Constructs & 1 & 2 & 3 & 4 \\
\hline Cognitive age & 0.92 & & & \\
Brand Loyalty & 0.059 & 0.90 & 0.92 & \\
Materialism & $-0.092^{*}$ & -0.054 & $0.542^{* *}$ & 0.86 \\
Status consumption & -0.056 & -0.022 & 2.64 & 2.77 \\
Mean & 3.42 & 4.80 & 1.49 & 1.50 \\
S.D & 1.00 & 1.61 & 0.81 & 0.66 \\
Extracted variance & 0.68 & 0.65 & & \\
\hline
\end{tabular}

*correlation significant at $\mathrm{p}<0.05$

$* *$ Correlation significant at $\mathrm{p}<0.01$

Table 6 LISREL Outcomes for Hypothesis Model

\begin{tabular}{llll}
\hline Path of hypothesis & Standardized estimation & t-value & Findings \\
\hline $\begin{array}{l}\text { H1: Association of cognitive } \\
\text { Age to materialism }\end{array}$ & -0.12 & -2.80 & Accepted and supported \\
$\begin{array}{l}\text { H2: Association of cognitive } \\
\text { Age to status consumption }\end{array}$ & -0.09 & -2.18 & Accepted and supported \\
$\begin{array}{l}\text { H3: Association of cognitive } \\
\text { Age to brand or product }\end{array}$ & 0.05 & 1.20 & Rejected/Not supported \\
loyalty & & & \\
\hline
\end{tabular}

\section{Results}

According to Table 7, there is empirical support that two of these three directly associated between different constructs, i.e., $\mathrm{H} 1$ and $\mathrm{H} 2$, were supported. The outcomes in this context presented a negative association of cognitive age with materialism and status consumption as indicated by $\mathrm{t}$ value, which is -2.80 and -2.18 , respectively. As the older consumers in Pakistan feel cognitively old, their motivation level and materialism level for social status are diminished. Concerning product or brand loyalty, there was no supportive evidence as $\mathrm{t}$ value was found to be1.20. Considering all these aspects, the hypothesis was presented that Pakistani seniors, who are cognitively elder, are more loyal to the brands than other people. The absence of significance is attributed to brands and product proliferation in the Pakistani market since liberalization. According to key evidence presented in table 8 , it is demonstrated that there is empirical support for five out of these six hypotheses regarding moderating impact.

Outcomes have indicated that self-confidence and social involvement can act as the major moderators for evaluating the impact of cognitive age on materialism, status consumption, and loyalty for the consumers, who are elders.

Table 7 Regression Coefficients across Low and High Levels of Moderator Variables (Unrestricted Run)

\begin{tabular}{lllllll}
\hline Hypotheses & Moderator & $\begin{array}{l}\text { Dependent } \\
\text { Moderator }\end{array}$ & $\mathbf{R}^{\mathbf{2}}$ & $\begin{array}{l}\text { Moderator } \\
\text { level }\end{array}$ & $\begin{array}{l}\text { Cognitive } \\
\text { Age }\end{array}$ & $\begin{array}{l}\text { Chow } \\
\text { Variable }\end{array}$ \\
\hline $\mathrm{H}_{1 \mathrm{a}}$ & Self & Materialism & 0.017 & High & -0.221 & $\mathrm{~F}=6.11^{* *}$ \\
& Confidence & & 0.016 & Low & $-0.185^{*}$ & \\
$\mathrm{H}_{1 \mathrm{~b}}$ & Social & Materialism & 0.001 & High & $-0.036^{*}$ & $\mathrm{~F}=10.35^{* * *}$ \\
& Involvement & & 0.003 & Low & -0.294 & \\
$\mathrm{H}_{2 \mathrm{a}}$ & Self & Status & 0.000 & High & -0.034 & $\mathrm{~F}=0.94(\mathrm{NS})$ \\
& Confidence & Consumption & 0.005 & Low & $0.153^{*}$ & \\
$\mathrm{H}_{2 \mathrm{~b}}$ & Social & Status & 0.003 & High & $0.087^{*}$ & $\mathrm{~F}=6.44^{* *}$ \\
& Involvement & Consumption & 0.021 & Low & $-0.207^{*}$ & \\
\hline
\end{tabular}




\begin{tabular}{lllllll}
\hline $\mathrm{H}_{3 \mathrm{a}}$ & Self & Loyalty to brand or & 0.031 & High & 0.284 & $\mathrm{~F}=10.33^{* * *}$ \\
& Confidence & product & 0.002 & Low & 0.072 & \\
$\mathrm{H}_{3 \mathrm{~b}}$ & Social & Loyalty to brand or & 0.000 & High & $-0.014^{*}$ & $\mathrm{~F}=14.15^{* * * *}$ \\
& Involvement & product & 0.000 & Low & 0.151 & \\
\hline
\end{tabular}

$* \mathrm{p}<0.10, * * \mathrm{p}<0.05, * * * \mathrm{p}<0.01$

\section{Moderating Effects Imposed by Self Confidence}

The moderating influence of self-confidence for $\mathrm{H} 1 \mathrm{a}$ and $\mathrm{H} 3 \mathrm{a}$ for elderly consumers is significant as presented by difference tests between the coefficient of regression of low and high self-confidence level during the exhibition of the materialistic tendencies as shown in Table 8 ( $p<0.5, F=6.11)$. Regarding loyalty, these values are $p<0.01$ and $F=10.33$. On the contrary to this, H2a, selfconfidence does not act as a moderator in the case. Where these elders show engagement regarding status consumption, as shown in Table 4 with $\mathrm{F}=0.94$. The explanation regarding this benefit of moderating effects produced by the self-confidence aspect for loyalty and materialism is that these have witnessed the transformation in the country's economic condition and have it growing as a liberalized economy. As the age of the consumers has increased, it is felt by the senior but cognitively young consumers that they have the time for the satisfaction of the materialistic craving they are having.

Also, loyalty to different new luxury product introductions in Pakistan after liberalization is considered essential and loyal to such products. Yet, self-confidence may not act as the moderator when the consumption for status is due to others' significance in Pakistani culture. In this regard, the prime fact is that several Pakistanis have their social identity from membership in a group.

\section{Moderating Effect Social Involvement}

For the hypotheses $\mathrm{H} 1 \mathrm{~b}, \mathrm{H} 2 \mathrm{~b}$, and $\mathrm{H} 3 \mathrm{~b}$, it is clear that moderating influence due to senior consumers' social involvement is significant. It is presented by the difference test between the coefficient of regression of high and low social involvement. In the case of the exhibition of materialistic tendencies, as shown in Table 8, where $\mathrm{p}<$ 0.01 and $\mathrm{F}=10.35$ and for status consumption motivation, the value presented in table 4 indicated $\mathrm{p}<0.05 \mathrm{~F}$ value is 6.44. For the loyalty associated with any brand, Table 4 represents values at $p<0.01$, while $F=14.15$. With the increase in the social involvement level, elders in Pakistan have the materialistic pleasure they want to enjoy. Moreover, they show loyalty to brands and products and want to consume for status.

\section{Discussion}

The present research was carried out the critical examination of the senior market in Pakistan by considering the cognitive age for the determination of association of cognitive age to the level of loyalty proneness, status consumption, and materialism level. The outcomes revealed that Pakistan seniors, who have a young cognitive age, are more materialists, and their motivation is social status. Marketers of these luxury products must market their products to the cognitively youngers because of their interest in meeting status needs. Ismail, Nguyen, and Melewar (2018) also demonstrated that the cognitive young senior's primary interest is not the style, but it is the status. Due to the increase in the Pakistani market's economic potential, especially older individuals having more wealth. Bhaduri and Stanforth (2016) also revealed that these seniors are the prime focus of luxurious brands. The studies also showed that social involvement and self-confidence are two significant moderators, which can influence the association between cognitive age and status consumption, materialism, and loyalty proneness (Ismail, 2017). The self-confidence moderator can influence the association between loyalty proneness, materialism, and cognitive age (Jain, 2018).

On the other hand, self-confidence has not influenced the association between status consumption and cognitive age. It is because of external and interpersonal motivations, for instance, social motivation and conspicuousness for presenting the social identity of a person instead of the internal motivation such as quality, experiential and reward have more impact on the motivation of seniors for status (Sulaiman, Ali, and Khatoon, 2019; Ashiq and Asad, 2017). This study also revealed the moderating effect of social involvement on materialism and cognitive age, loyalty proneness, and status consumption. It is associated with the interdependent self-idea consistent with the significance of family for elders in Pakistan. The outcomes also presented that subjective norms can influence buying luxury brands as presented by Ajitha and Sivakumar (2017). It can help explain that instead of personal perception, the intention to buy a luxury brand is affected by how others perceive their behavior to buy the luxury brand. Bhaduri and Stanforth (2016) revealed that luxury consumption is a status symbol in Pakistani society. Considering materialism, Correia, Kozak, and Kim (2019) demonstrated that materialistic people pay more respect and respect to people based on their motivation. Therefore, in Pakistan, the luxury purchase is often motivated by status consciousness.

As illustrated in results, there is an impact on marketing variables by elderly Pakistanis having the value of social relationships (Sulaiman, Ali, and Khatoon, 2019). Cognitively, while consuming, younger consumers may take out their social identity. Moreover, one study explored that people like and enjoy social involvement. The results show, marketers need to consider social relationships as there is a suggestion by having the impact of social involvement. It is exceptionally valid for wellknown brands that they provide a significant role while 
developing the social identity for reasoning younger seniors of Pakistan. Marketers need to consider marketing the collective cultural feature of Pakistanis seniors, such as a family, as it motivates psychological needs for luxury products and brands. As luxury marketers need to worry about their branded products' social features and support individual seniors, there must be a social identity of collective group and family. The investigation is needed to see that this study holds on other emerging markets with collectivist cultures while having a moderating impact on repute consumption of social involvement (Bhaduri and Stanforth, 2016, Islam et al., 2017). There is a worthwhile suggestion for luxury marketers in these markets, primarily because the products related to individualistic cultures are conspicuous consumption and hedonic elements. The outcomes further presented that paying a particular focus on the perspective of social involvement. Luxury marketers can reach the status-interested cognitive younger older in Pakistan's collectivist culture as a means of increased social comparison and identity.

\section{Contribution, Limitation, and Future Research}

One of this research's exceptional contributions

is that this is one of the initial investigations, which has examined the Pakistani market. This study has presented the influence of the cognitive age construct and its effect on different variables. This study considered the Pakistani market's specificities and presented the significance of social involvement regarding the impact produced by cognitive age on brand loyalty, materialism, and status consumption. Yet, it is recognized that future studies can study several other variables. The evaluation of different variables by cognitive age is required to provide a clear picture of the influence of cognitive age on Pakistan's consumption patterns. For instance, this study demonstrated the significance of social involvement.

In contrast, future studies can understand the influence of social positioning in the Pakistan seniors and present the influence of image and materialism. On the other hand, considering status consumption, research is required to determine the external motivation, which can affect this interest and its relation to purchasing behavior. Furthermore, research studies are also required to examine cultural variables for Pakistani culture, for example, power distance and collectivism. Future studies must also investigate contextual elements in Pakistan, influencing the older consumer to feel younger cognitively (Correia, Kozak, and Kim, 2019; Bhaduri and Stanforth, 2016).

Future research can also determine how Pakistani seniors meet social involvement needs in changing family structure. Additionally, data is from Karachi, so it isn't easy to generalize the outcomes for populations in another area from Pakistan. Another critical point of consideration is that the current sample is from urban areas. There is a need for replication of information to collect information related to rural areas. Females dominate the older population in rural areas. Thus, more studies are required to present a clear reflection of the country. Considering the methodological perspective, fit indices of this study revealed that it just lies in the acceptable criteria required for a good fit. Thus, there is a crucial need for developing appropriate measures for the emerging markets, which can reflect complete information related to the topic.

As presented by this research, cognitive age is considered a prime segmentation variable for Pakistan's elderly market. Further studies are required to present the association between different constructs of consumers' behavior and cognitive age, for instance, materialism and status consumption. Conclusively, this research revealed that social involvement is an essential factor for older people, influencing this kind of association (Pino, Guido, and Nataraajan, 2017; Bhaduri and Stanforth, 2016). Due to the Pakistani market's size and significance, this research has provided a greater contribution to the everneeded research in the Pakistani market.

\section{References}

1. Aaker, David. Managing Brand Equity. New York, NY: The Free Press, A Division of Macmillan, Inc, 1991.

2. Ajitha, S., and Sivakumar, V. J. (2017). Understanding the effect of personal and social value on attitude and usage behavior of luxury cosmetic brands. Journal of Retailing and Consumer Services, 39, 103-113.

3. Amatulli, C., De Angelis, M., Korschun, D., and Romani, S. (2018). Consumers' perceptions of luxury brands' CSR initiatives: An investigation of the role of status and conspicuous consumption. Journal of cleaner production, 194, 277-287.

4. Amatulli, C., Guido, G., and Nataraajan, R. (2015). Luxury purchasing among older consumers: exploring inferences about cognitive age, status, and style motivations. Journal of Business Research, 68(9), 1945-1952.

5. Ashiq, U., and Asad, A. Z. (2017). The rising old age problem in Pakistan. Journal of the Research Society of Pakistan-Vol, 54(2).

6. Barak, B. and L.G. Schiffman (1981). Cognitive Age: A nonchronological age variable. Advances in Consumer Research, 8, 602-606.

7. Bhaduri, G., and Stanforth, N. (2016). Evaluation of absolute luxury: effect of cues, consumers' need for uniqueness, product involvement and product knowledge on expected price. Journal of Fashion Marketing and Management: An International Journal, 20(4), 471-486.

8. Chowdhury, R. M., \& Fernando, M. (2013). The role of spiritual well-being and materialism in determining consumers' ethical beliefs: An empirical study with Australian consumers. Journal of Business Ethics, 113(1), 61-79.

9. Chua, C., Cote, J. A., \& Leong, S. M. (1990). The antecedents of cognitive age. Advances in consumer research, 17(1).

10. Correia, A., Kozak, M., and Kim, S. (2019). Investigation of luxury values in shopping tourism 
using a fuzzy-set approach. Journal of Travel Research, 58(1), 77-91.

11. Cristofalo, V. J. (1988). An overview of the theories of biological aging. In J. E. Birren \& V. L. Bengtson (Eds.), Emergent theories of aging (pp. 118-127). New York: Springer.

12. Deary, I. J., Whiteman, M. C., Pattie, A., Starr, J. M., Hayward, C., Wright, A. F., ... \& Whalley, L. J. (2004). Apolipoprotein e gene variability and cognitive functions at age 79: a follow-up of the Scottish cognitive survey of 1932. Psychology and aging, 19(2), 367.

13. Dogan, V. (2015). The effect of materialism and proximity of clothing to self on the ratio of feeling younger: implications for the consumption experiences of older people in Turkey. International journal of consumer studies, 39(5), 564-573.

14. Eastman, J.K. and R. Iyer (2005). The impact of cognitive age on internet use of the elderly: An introduction to the public policy implications. International Journal of Consumer Studies, 29(March), 125-136.

15. Flynn, L. R., Goldsmith, R. E., \& Pollitte, W. (2016). Materialism, status consumption, and market involved consumers. Psychology \& Marketing, 33(9), 761-776.

16. Islam, T., Wei, J., Sheikh, Z., Hameed, Z., and Azam, R. I. (2017). Determinants of compulsive buying behavior among young adults: The mediating role of materialism. Journal of adolescence, 61, 117-130.

17. Ismail, A. R. (2017). The influence of perceived social media marketing activities on brand loyalty: The mediation effect of brand and value consciousness. Asia Pacific Journal of Marketing and Logistics, 29(1), 129-144.

18. Ismail, A. R., Nguyen, B., and Melewar, T. C. (2018). Impact of perceived social media marketing activities on brand and value consciousness: roles of usage, materialism and conspicuous consumption. International Journal of Internet Marketing and Advertising, 12(3), 233-254.

19. Iyer, R. A. J. E. S. H., Reisenwitz, T. H., and Eastman, J. K. (2008). The impact of cognitive age on seniors' lifestyles. Marketing Management Journal, 18(2), 106-118.

20. Iyer, R., Eastman, J. K., Sharma, R. W., and Eastman, K. L. (2017). The Impact Of Cognitive Age On Materialism, Status Consumption And Loyalty Proneness On The Indian Elderly. Marketing Management Journal, 27(1).

21. Jacoby, J., \& Chestnut, R. W. (1978). Brand loyalty: Measurement and management.

22. Jain, V. (2018). Luxury: not for consumption but developing extended digital self. Journal of Human Values, 24(1), 25-38.

23. Jain, V. (2018). Luxury: not for consumption but developing extended digital self. Journal of Human Values, 24(1), 25-38.
24. Jones, M. A., and Reynolds, K. E. (2006). The role of retailer interest on shopping behavior. Journal of Retailing, 82(2), 115-126.

25. Karasawa, M., Curhan, K. B., Markus, H. R., Kitayama, S. S., Love, G. D., Radler, B. T., \& Ryff, C. D. (2011). Cultural perspectives on aging and well-being: A comparison of Japan and the United States. The International Journal of Aging and Human Development, 73(1), 73-98.

26. Ki, C., Lee, K., and Kim, Y. K. (2017). Pleasure and guilt: how do they interplay in luxury consumption?. European Journal of Marketing, 51(4), 722-747.

27. Lambert-Pandraud, R., Laurent, G., \& Lapersonne, E. (2005). Repeat purchasing of new automobiles by older consumers: empirical evidence and interpretations. Journal of Marketing, 69(2), 97-113.

28. Lang, C., \& Armstrong, C. M. J. (2018). Collaborative consumption: The influence of fashion leadership, need for uniqueness, and materialism on female consumers' adoption of clothing renting and swapping. Sustainable Production and Consumption, 13, 37-47.

29. Lipke, David J. (2001), "Pledge of Allegiance," American Demographics, 22 (11), 40-43.

30. Mathur, A., \& Moschis, G. P. (2005). Antecedents of cognitive Age: A replication and extension. Psychology \& Marketing, 22(12), 969994.

31. McCormick, B. J., Richard, S. A., Caulfield, L. E., Pendergast, L. L., Seidman, J. C., Koshy, B., ... \& Rasmussen, Z. (2019). Early life child micronutrient status, maternal reasoning, and a nurturing household environment have persistent influences on child cognitive development at age 5 years: results from MAL-ED. The Journal of Nutrition, 149(8), 14601469.

32. Osmonbekov, T., Gregory, B. T., Brown, W., \& Xie, F. T. (2009). How consumer expertise moderates the relationship between materialism and attitude toward advertising. Journal of Targeting, Measurement and Analysis for Marketing, 17(4), 321-327.

33. Parpis, Eleftheria (2002), "Shades of Gray," Adweek, 43 (43), 18-20.

34. Pino, G., Guido, G., and Nataraajan, R. (2017). Iconic art infusion in luxury retail strategies: Unveiling the potential. Journal of Global Scholars of Marketing Science, 27(2), 136-147.

35. Raju, P. S. (1980). Optimum stimulation level: Its relationship to personality, demographics, and exploratory behavior. Journal of Consumer Research, 7(December), 272-282.

36. Rosenbaum-Elliott, R., Percy, L., \& Pervan, S. (2015). Strategic brand management. Oxford University Press, USA.

37. Sirgy, M.J., E. Gurel-Atay, D. Webb, M. Cicic, M. Husic, A. Ekici, A. Hermann, I. Hegazy, D.-J. Lee, and J.S. Johar (2012). Linking advertising, 
materialism, and life satisfaction. Social Indicators Research, 107(May), 79-101.

38. Smith, R. B., \& Moschis, G. P. (1985). A Socialization Perspective on Selected Consumer Characteristics of the Elderly. Journal of Consumer Affairs, 19(1), 74-95. doi: 10.1111/j.17456606.1985.tb00345.x

39. Sprott, D., Czellar, S., \& Spangenberg, E. (2009). The importance of a general measure of brand engagement on market behavior: Development and validation of a scale. Journal of Marketing Research, 46(1), 92-104.

40. Srivastava, R. K. (2007). DETERMINATION OF BRAND LOYALTY FACTORS AGE GROUP-1824. Academy of Marketing Studies Journal, 11(1).

41. Sulaiman, N., Ali, K., and Khatoon, M. (2019). Impact of Social Pressures on Materialism among Students. Journal of Educational Research, 22(1), 61.

42. Swimberghe, K., Darrat, M. A., Beal, B. D., and Astakhova, M. (2018). Examining a psychological sense of brand community in elderly consumers. Journal of Business Research, 82, 171178.

43. Szmigin, I., \& Carrigan, M. (2001). Learning to love the older consumer. Journal of Consumer Behaviour: An International Research Review, 1(1), 22-34.

44. Tarka, P., (2019). Influence of Materialism on Compulsive Buying Behavior: General Similarities and Differences Related to Studies on Young Adult consumers in Poland and US. Journal of International Consumer Marketing, 32(3). doi: 10.1080/08961530.2019.1695240

45. Touzani, M., \& Temessek, A. (2009). Brand loyalty: Impact of cognitive and affective variables.

46. Wilkes, R. E. (1992). A structural modeling approach to the measurement and meaning of cognitive age. Journal of Consumer Research, 19, 292-301

47. Zia, A., Ifthikar, M., and Raza, S. H. (2017). Mediating Role of Individual. s Ethical Belief in Determining the Influence of the Mobile Networks TV Advertisements on Moral Behavior of Youth in Pakistan. Pakistan Vision, 18(2), 146-162. 